\title{
Phytochemical and Chromatographic Screening of Extracts of Acanthospermum Hispidum DC (Asteraceae)
}

Jotham Yhi-pênê N'DO*, Dramane Pare, Adama Hilou

Laboratory of Biochemistry and Applied Chemistry (LABIOCA) / University Joseph KI-ZERBO, 03 BP 848 Ouagadougou 03, Burkina Faso

DOI: $10.36348 /$ sijcms.2019.v02i07.001 | Received: 03.11.2019| Accepted: 10.11 .2019 | Published: 12.11 .2019

*Corresponding author: Jotham Yhi-pênê N'DO

\section{Abstract}

General: Asteraceae are a plant family widely used in traditional medicine. Acanthospermum hispidum highlighted in this work is very rich in therapeutic molecules. Objective: This study consisted in highlighting the wealth of molecules of interest of Acanthospermum hispidum. Methodology: Phytochemical screening carried out through characterization tests to concern certain secondary metabolites such as tannins, alkaloids, terpenes, flavonoids. Chromatographic studies were used for the analysis of the various extracts of Acanthospermum hispidum. Results: The characterization tests showed the presence of tannins, flavonoids, alkaloids and triterpenes, while the saponosides were found in the methanolic and aqueous fraction of the ethaolic extract of Acanthospermum hispidum. Chromatographic tests were found in the various extracts of the metabolites of interest such as flavonoids and terpene compounds. Conclusion: These results are probably a scientific source for the use of Acanthospermum hispidum as a medicinal plant. The high use of this plant could be explained for its wealth of secondary metabolites.

Keywords: Acanthospermum hispidum, Phytochemistry, Chromatographic analyzes.

Copyright @ 2019: This is an open-access article distributed under the terms of the Creative Commons Attribution license which permits unrestricted use, distribution, and reproduction in any medium for non-commercial use (NonCommercial, or CC-BY-NC) provided the original author and source are credited.

\section{INTRODUCTION}

Asteraceae or Compositae constitute one of the largest families of Angiosperms [1], containing more than 1,500 genera $(25,000$ known species) or nearly $10 \%$ of the total flora of the world [2]. Although $98 \%$ of Asteraceae are herbaceous, shrubs, lianas, trees, there are also some aquatic species. The main characteristic of this family is the presence of many flowers united in a capitulum.

The genus Acanthospermum includes annual herbaceous plants that are erect or prostrate. The leaves are simple, opposite, with dentate or entire margins, and the inflorescence is axial or terminal, with yellow flowers [3].

Acanthospermum hispidum "the goat's head" is an annual plant of the family Asteraceae. It is native to tropical America and is an important medicinal plant in India. The species is easily identifiable and grows abundantly during the rainy seasons.

Acanthospermum hispidum DC (Asteraceae) is an herb taken from an ethnobotanical survey conducted in 2014 that identified the medicinal plants used in the management of liver diseases by traditional medicine in Burkina Faso.

This work has allowed through a phytochemical screening to highlight the secondary metabolites of interest and thin layer chromatographic methods to highlight the diversity of molecules contained in extracts of Acanthospermum hispidum.

\section{METHODOLOGY}

\section{Extraction by Ethanol Maceration}

Fifty grams $(50 \mathrm{~g})$ of the whole plant powder are extracted with stirring for 24 hours with $1000 \mathrm{~mL}$ of ethanol. After filtration under reduced pressure, the filtrate is frozen and freeze-dried.

\section{Splitting by liquid / liquid extraction}

The ethanol extract was fractionated using solvents of increasing polarity: hexane, dichloromethane, ethyl acetate and methanol. The solvents were removed under reduced rota-steam pressure. The concentrated fractions were dried in an oven. These fractions were used for the different tests. 


\section{Extraction by Aqueous Decoction}

One hundred grams $(100 \mathrm{~g})$ of powder was put in a flask and $500 \mathrm{ml}$ of distilled water was added thereto. The mixture is homogenized and boiled under reflux for 30 minutes. Then he is allowed to warm up. The contents of the flask are spilled in centrifuge tubes. And the supernatant is concentrated, frozen and freezedried.

\section{Phytochemical Screening Tests}

The general characterization tests are intended to reveal the main chemical compounds present in the plant extracts. These tests were performed on extracts and extracts of Acanthospermum hispidum extract. The procedures described by Nacoulma [4] were used for the demonstration of different chemical groups (tannins and polyphenols, flavonoids, terpenes, saponosides and alkaloids).

Libermann-Bürchard test: it allows the detection of steroids and triterpenes [5]. Each residue is dissolved in an acetic anhydride-chloroform mixture (1: $1 \mathrm{v} / \mathrm{v}$ ) in a test tube. Two $\mathrm{mL}$ of concentrated $\mathrm{H}_{2} \mathrm{SO}_{4}$ was gently added to the top of the tube. At the separation zone of the two solvents a red-brown ring is formed, indicating the presence of sterols and triterpenes.

Shibata test: this is the detection of flavonoids $[5,6]$. Each sample is dissolved in $2 \mathrm{~mL}$ of $50^{\circ}$ methanol. Fragments of magnesium turn and 4 drops of $\mathrm{HCl}$ (concentrate) were added to each tube. The appearance of a red or orange color indicates the presence of flavonoid aglycones.

$\mathrm{FeCl}_{3}$ test: it characterizes tannins and polyphenols. The sample was dissolved in $2 \mathrm{~mL}$ of distilled water, 3 drops of $1 \% \mathrm{FeCl}_{3}$ were added. The appearance of a blue-black or green-blackish coloration indicates the presence of gallic tannins or catechinic tannins respectively [5].

Foam test: Each sample is dissolved in 2-3 mL of distilled water in a test tube. The tube is shaken vigorously. The appearance of a column of mosses at least $1 \mathrm{~cm}$ in height, persisting for at least 15 minutes, indicates the presence of saponosides [5].

\section{Analysis of the compounds by chromatography Analytical thin layer chromatography}

Analytical thin layer chromatographic plates, glass support (Silicagel ${ }^{\circledR} 60$ F254, $250 \mu \mathrm{m}$, Merck, Germany) were used for the analysis of extracts and fractions of Acanthospermum hispidum. These were developed in conventional glass tanks (Camag), whose atmosphere was previously saturated with mobile phase vapors. Binary or ternary mobile phases based on ethyl acetate, formic acid or analytical grade glacial acetic acid were used. The spots were revealed at UV 254/365 $\mathrm{nm}$ before and after Neu reagent spraying.

\section{Column Chromatography}

The ethyl acetate extract $(1 \mathrm{~g})$ was dissolved in $1 \mathrm{ml}$ of $\mathrm{CH}_{2} \mathrm{Cl}_{2} / \mathrm{MeOH}$ (50:50) and then subjected to LH-20 column adsorption chromatography (diameter: 4 $\mathrm{cm}$; column: $25 \mathrm{~cm}$ ). The eluting solvent is $\mathrm{CH}_{2} \mathrm{Cl}_{2} /$ $\mathrm{MeOH}(50: 50$ and 20:80 v / v).

\section{RESULTS \\ Phytochemical Screening}

Qualitative phytochemical tests have highlighted the large groups of secondary metabolites in the extracts. The results are presented in tabular form (Table-1).

Table-1: Phytochemical Screening

\begin{tabular}{|l|l|l|l|l|l|l|l|}
\hline Secondary Metabolites & Taq & Teth & FH & FD & FA & FM & FE \\
\hline tannins & ++ & ++ & + & + & +++ & +++ & ++ \\
\hline flavonoids & ++ & ++ & - & + & ++ & ++ & + \\
\hline alkaloids & ++ & + & + & + & - & - & - \\
\hline saponosides & + & - & - & - & - & +++ & ++ \\
\hline triterpenes / steroids & + & ++ & ++ & ++ & ++ & + & + \\
\hline
\end{tabular}

Presence: +; Absence: -; Taq: aqueous crude extract, Teth: ethanolic crude extract, FD: dichloromethane fraction, FA: ethyl acetate fraction, FM: methanol fraction, FE: aqueous fraction.

The phenolic compounds and the terpenes are distributed in the extracts of the plant according to their affinities for certain extraction solvents.

\section{Results of thin layer chromatography of plant extracts}

Thin layer chromatography (TLC) revealed a few secondary metabolites contained in the extracts and extracts fractions of the whole plant of Acanthospermum hispidum. Thus the analysis of the extracts was carried out using fluorescent plates, an eluent system established according to the compounds to be separated and reagents. The chromatograms were revealed at the respective wavelengths of $254 \mathrm{~nm}$ and $365 \mathrm{~nm}$ before and after spraying with the NEU reagent for the purpose of revealing flavonoids and phenol acids. Thus the first system (system 1) used was: ethyl acetate, methanol, acetic acid, water (71/13/5/11).

The observation of the TLC plates (b) shows the presence of distinctly separated spots in the crude ethanolic extract with yellow, orange and blue stains, 
after spraying the plate with the Neu reagent. The yellow and orange stains are more concentrated in the ethyl acetate fraction compared to the other fractions after spraying with Neu reagent (Fig-1).

The chromatogram of extracts and extracts fractions of Acanthospermum hispidum DC, and references after spraying with the reagent of $\mathrm{Neu}(\mathrm{d})$, showed the presence of quercetin in the crude ethanolic extract and in the ethyl acetate fraction with a frontal reference of 0.41 . The methanol fraction contains blue phenol acids (Fig-1).
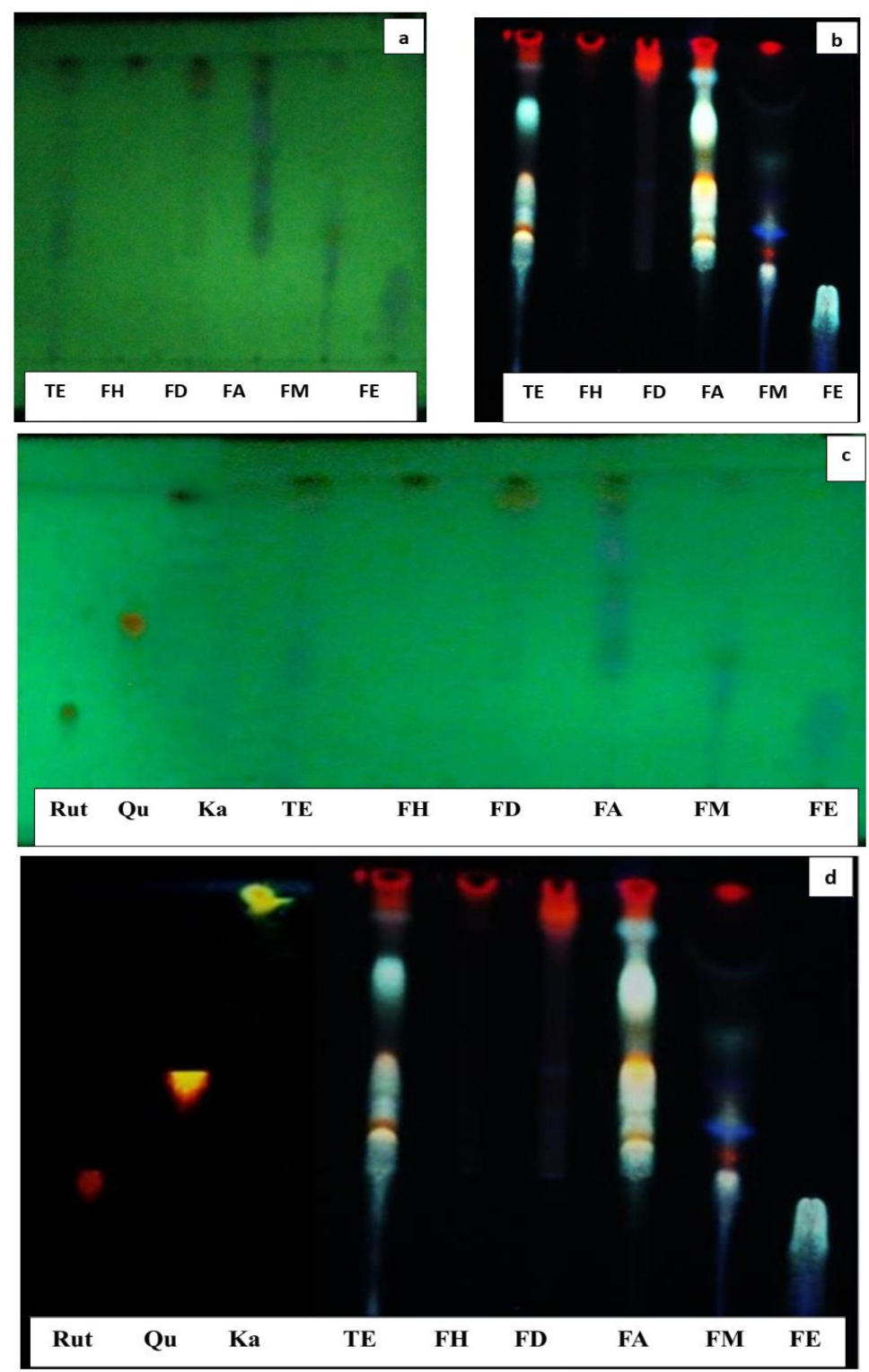

Fig-1: Thin-layer Chromatographic Profile of extracts and fractions of Acanthospermum hispidum DC, and some flavonoids (reference compounds)

TE: Ethanolic extract, TA: Aqueous extract, FH: Hexane fraction, FD: Dichloromethane fraction, FA: Ethyl acetate fraction, FM: Methanol fraction, FE: Ethanol-water fraction, Rut: Rutin, Qu: Quercetin, Ka: kaempferol.

Figures 2(a) to (f) show the profile of the two forms of extracts of Acanthospermum hispidum and quercetin separated with the system 2: ethyl acetate, formic acid, glacial acetic acid, water, (10/1, $1 / 1.1 /$ 2.6). The plate was observed in the visible ( $a$ and $b$ ),
UV $254 \mathrm{~nm}$ (c and d) and UV $365 \mathrm{~nm}$ (e and f) before and after spraying the NEU reagent. Quercetin orange is present in the ethanolic extract.

Figures (h) to (i) show the profile of the two forms of extracts and the silymarin (reference compound) separated with the system 3: chloroform, acetone, formic acid (75/ 16.5 / 8.5). Silymarin was not observed in the extracts by this method (Fig-2). 
Figures (j) and (k) show the profile of the two forms of extracts after spraying with the reagents of Libermann Buchard using the system 2. These chromatograms show in the visible (j) and at $365 \mathrm{~nm}$ (k) a presence relatively higher terpenes in the ethanolic extract than the aqueous extract.
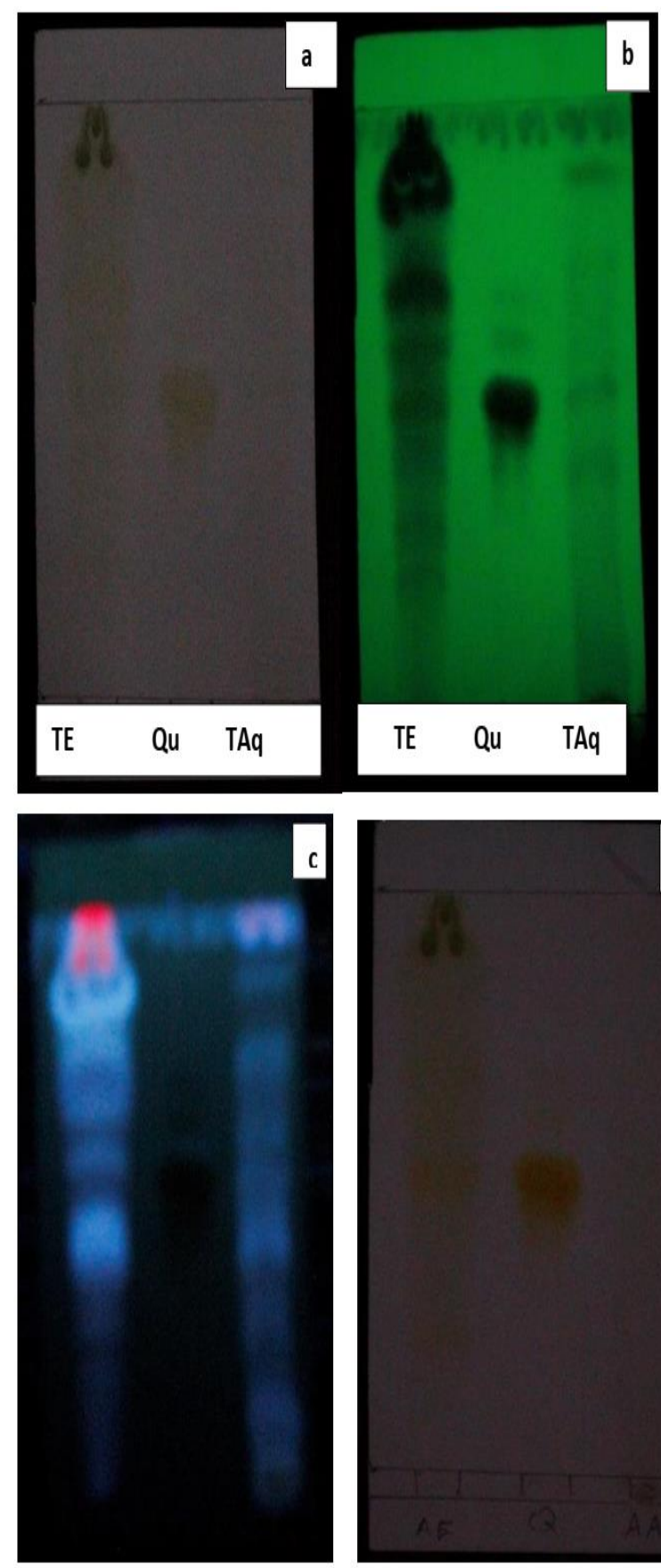

As a summary, it should be noted that the ethanolic macerate of the whole plant of Acanthospermum hispidum contains more flavonoid compounds (quercetin for example) of yellow or orange color and terpene compounds of violet or brown color compared to the aqueous decoction which contains mainly acids phenols of blue color (Fig-2).
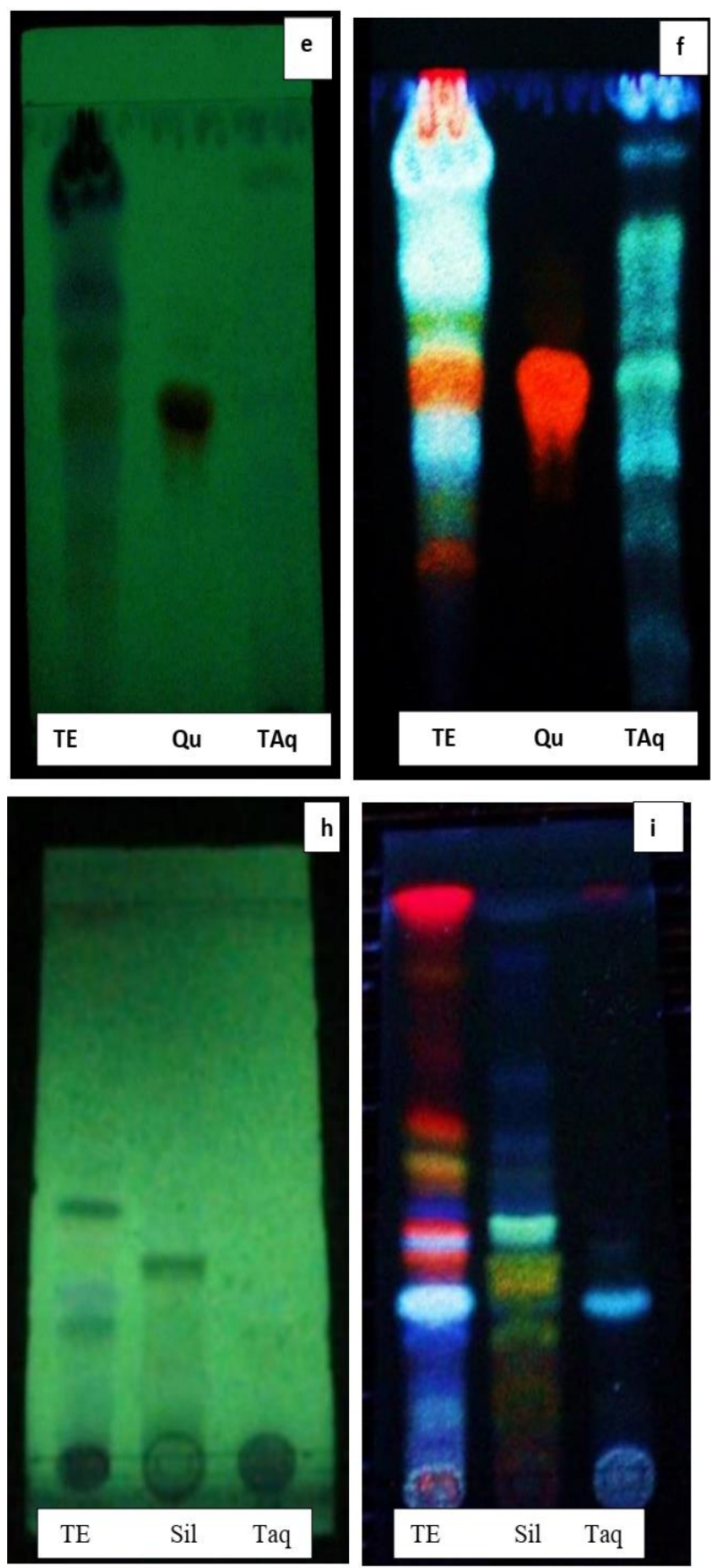


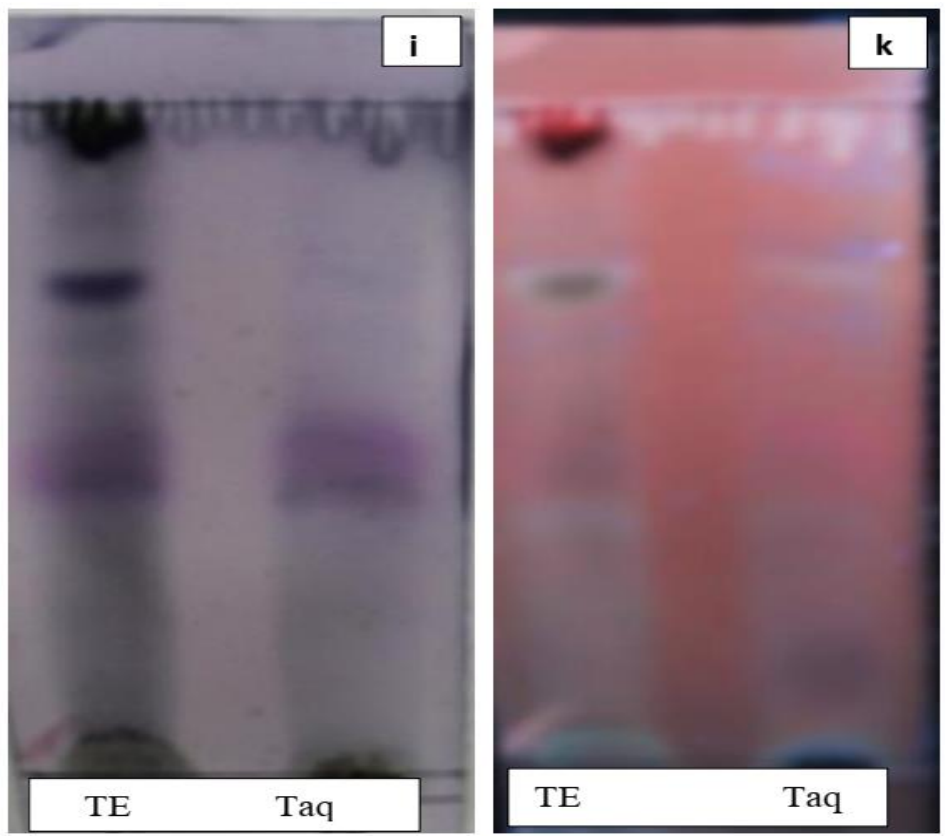

Fig-2: Chromatogram of the two forms of extracts of Acanthospermum hispidum DC with quercetin and silymarin (two reference compounds)

TE: Ethanolic extract, Qu: Quercetin, Taq: Aqueous extract, Sil: Silymarin

The chromatogram of the fractions of the ethanolic extract showed spots of yellow, orange color in the ethyl acetate fraction after spraying with $\mathrm{Neu}$, this highlights the flavonoids [7] whose content in this fraction was the most important. Flavonoids are recognized to possess several biological properties including hepatoprotection [8].

\section{Result of the column chromatography of the ethyl acetate fraction}

Thirty-three (33) $15 \mathrm{~mL}$ fractions each were collected. After analysis by TLC, these fractions were grouped into four main fractions (I-IV).

Table-2: The masses of the sub fraction of the ethyl acetate fraction

\begin{tabular}{|l|l|l|}
\hline Extracts & Mass of fractions (mg) & Yield (mg / 100 mg) \\
\hline F1-4 & 72 & 7,2 \\
\hline F5-20 & 107 & 10.7 \\
\hline F21-28 & 127 & 12.7 \\
\hline F29-33 & 93 & 9.3 \\
\hline
\end{tabular}

These methods make it possible to confirm the richness of the ethanolic extract in hepatoprotective compounds and to attest to the best results (hepatoprotective, anti-inflammatory and biomembrane protection activities) obtained with the ethyl acetate fraction, which in addition to contain these different hepatotropic molecules [9].

\section{DISCUSSION}

Phytochemical screening has shown in addition to phenolic compounds, the presence of alkaloids and terpenes in the extracts. The presence of these secondary metabolites such as flavonoids and terpenes highlighted in phytochemical screening was confirmed by the assay results.

TLC results confirm phenol, total flavonoid, and total terpenes. Thus, the total phenol, total flavonoid and total terpenes content of Acanthospermum hispidum extracts and fractions correlate with antioxidant test results [10].
Some flavonoids are known for their hepatoprotective properties [11]. This is the case of silybinin, also known as silybin, which is the main active component of silymarin, a mixture of silybin, isosilybin, silydianine and silychristin, extracted from the seeds of an Asteraceae, Silybum marianum (milk thistle) [12]. It is used in the treatment and prevention of liver diseases through its anti-hepatotoxic properties [13]. Chemically modified silybinin in the form of silibinin dihydrogen disodium disuccinate (Trade name Legalon SIL), a solution for injection, is used in the treatment of severe conditions with hepatotoxic substances, such as during phalloid amanita poisoning.

The triterpenes and tetraterpenes highlighted in these works have several biological properties. Bcarotene is a typical example of carotenoids with provitamin function. It undergoes enzymatic conversion to vitamin A primarily in the intestine and liver [14]. Thanks to their long polyunsaturated carbon chain, 
carotenoids have an anti-radical activity. They were particularly effective against singlet oxygen, an excited state of oxygen. This property has been demonstrated especially for lycopene which possesses a hepatoprotective capacity [15].

The alkaloids, for their part, act on the central nervous system as depressants, as a stimulant or on the autonomic nervous system as sympathomimetic, parasympathomimetic, anti-cholinergic. They are also curarisers, local anesthetics, antifibrillants and amoebicides $[16,17]$. They also play an ecological role of defense against herbivores, however, they find several pharmaceutical applications in humans.

\section{CONCLUSION}

The terpene compounds detected in the extracts in addition to the phenolic compounds highlight the richness in natural substances extracts Acanthospermum hispidum. Each group of compounds highlighted in the extracts of the plant constitutes a therapeutic potential. This probably justifies the use of this plant in traditional medicine against liver diseases.

\section{ACKNOWLEDGEMENTS}

Characterization tests and chromatographic tests were carried out $\mathrm{t}$ at the Laboratory of Biochemistry and Applied Chemistry (LABIOCA) of the University Joseph KI-ZERBO.

\section{REFERENCES}

1. Cronquist, A. (1981). An integral system of classifi cation of fl owering plants. New York: Columbia University Press.

2. Verdi, L. G., Brighenete, I. M. C., \& Pizzolatti, M. G. (2005). Gênero Baccharis (Asteraceae): Aspectos químicos, econômicos e biológicos. Quim Nova, 28, 85-94.

3. Mallmann, R., Ethur, E. M., Bianchetti, P., Faleiro, D., Hoehne, L., \& Goettert, M. I. (2018). Effectiveness of aqueous and hydroalcoholic extracts of Acanthospermum australe (Loefl.) Kuntze against diarrhea-inducing bacteria. Brazilian Journal of Biology, 78(4), 619624.

4. Nacoulma, O. G. (1996). Plantes médicinales et Pratiques médicinales Traditionnelles au BURKINA. Université de Ouagadougou, Tome I, 65-68.

5. Ciulei, I. (1982). Methodology for Analysis of Vegetable Drugs. Practical Manual on the Industrial Utilisation of Medicinal and Aromatic Plants (Bucharest). Bucharest.

6. Chang, C., Yang, M., Wen, H., \& Chern, J. (2002). Estimation of Total Flavonoid Content in Propolis by Two Complementary Colorimetric Methods. Journal of Food and Drug Analysis,
10(3), 178-182.

7. Panche, A. N., Diwan, A. D., \& Chandra, S. R. (2016). Flavonoids: An overview. Journal of Nutritional Science, 5.

8. Wang, T. Y., Li, Q., \& Bi, K. S. (2018). Bioactive flavonoids in medicinal plants: Structure, activity and biological fate. Asian Journal of Pharmaceutical Sciences, 13(1), 12-23.

9. N'do, J. Y., Hilou, A., Pare, D., Sombie, E. N., Traoré, T. K., \& Tibiri, A. (2019). In vivo hepatoprotective potential and antioxidant properties of fractions derived from the ethanolic extract of Acanthospermum hispidum DC. Journal of Global Biosciences, 8(3), 6100-6119.

10. Alidadi, S., Moradi, M., Asadi-samani, M., \& Lorigooini, Z. (2017). Antioxidant Potential and Total Phenolic Compounds of Extracts and Fractions of Pistasia atlantica. International Journal of Pharmaceutical and Clinical Research, 9(4), 293-297.

11. Duda-Chodak, A., Tarko, T., Satora, P., \& Sroka, P. (2015). Interaction of dietary compounds, especially polyphenols, with the intestinal microbiota: a review. European Journal of Nutrition, 54(3), 325-341.

12. Himaja, N. (2015). Comparitive study of hepatoprotective activity of acanthospermum hispidum plant extract and herbal niosomal suspension against anti-tubercular drug induced hepatotoxicity in rats. Asian Journal of Pharmaceutical and Clinical Research, 8(5), 301304.

13. Kim, S. H., Oh, D. S., Oh, J. Y., Son, T. G., Yuk, D. Y., \& Jung, Y. S. (2016). Silymarin Prevents Restraint Stress-Induced Acute Liver Injury by Ameliorating Oxidative Stress and Reducing Inflammatory Response. Molecules, 21(443), 10.

14. Iqubala, A., Iqubalb, M. K., \& Haquea, S. E. (2014). Antioxidant activity of ethanolic extracts of callicarpa linata leaf. Pharmacologyonline, 3(11), 121-125.

15. Guenne, S. (2014). Potentiels Hépatoprotecteurs de trois (03) Asteraceae utilisées en médecine traditionnelle du Burkina Faso: Chrysanthellum americanum (L.) Vatke, Eclipta alba (L.) Hassk. et Vernonia colorata (Willd.) Drake. Université de Ouagadougou. Université de Ouagadougou.

16. Bruneton, J. (1999). Pharmacognosie, phytochimie et plantes médicinales (5th ed.). La Voisier TEC et DOC, Paris.

17. Xu, Y. J., Foubert, K., Dhooghe, L., Lemière, F., Maregesi, S., Coleman, C. M., ... Pieters, L. (2012). Rapid isolation and identification of minor natural products by LC-MS, LC-SPE-NMR and ECD: Isoflavanones, biflavanones and bisdihydrocoumarins from Ormocarpum kirkii. Phytochemistry, 79, 121-128. 